HARDY-RAMANUJAN JOURNAL 34 \& 35 (2013), 64-70

\title{
K. RAMACHANDRA: REMINISCENCES OF HIS STUDENTS
}

\section{A. Sankaranarayanan}

Professor K. Ramachandra: One of the Indian legends whom I know intimately

I am doubly fortunate to have had Professor Ramachandra as my PhD thesis advisor. He has not only been an excellent researcher but also a good teacher. I had the opportunity to learn many intricate techniques in Number Theory from him and I am extremely happy about it. We had indeed collaborated on several research works and some of our results have still been unimproved for several years.

Prof. Ramachandra has contributed in various branches of Number Theory.

1. Algebraic Number Theory: On Kronecker's limit formula.

2. Transcendental Number Theory: On Baker's theory on linear forms and logarithms, transcendental measures of certain irrational numbers and so on.

3. Theory of the Riemann zeta-function and $L$-functions: His contributions in this area are immense. I quote a few here namely, Omega theorems, lower and upper bound estimates on various questions, zero-density estimates of certain $L$-functions, Mean-value theorems on certain vertical lines of certain $L$-functions and so on.

4. Elementary Number Theory: Various questions involving summatory functions of several interesting arithmetical functions, On Vinogradov's three primes theorem and so on.

Personally, he was a nice gentleman. He was my mentor, teacher and above all, he was an excellent caretaker. I recall here my student days. I used to stay in Room No : 414 at the Brahmagupta Hostel. Generally I used to work until late night. On several occasions, he had visited my room even after midnight to discuss mathematical problems and poured several nice ideas.

He is one of the most successful mathematicians who had a lot of students. Prof. T. N. Shorey, Prof. S. Srinivasan, Prof. R. Balasubramanian, Prof. M. J. Narlikar, Prof. V. V. Rane, myself, Prof. K. Srinivas and Mr. Kishore Bhat (I learn that he has submitted his thesis to Mysore University recently) are all his PhD students.

Truly speaking, a very few of his students had certain privileges with him and definitely I was one among them. On special days of every year, he had invited me to his home for having lunch or dinner with him and his family. My relationship with Prof. Ramachandra is beyond a student and teacher relationship. I have been treated all along as one of his family members. He was more than a father figure to me and I truly owe him a lot to my existence.

One of his nice qualities was that whenever a student of his contributed some good mathematical results, he used to appreciate openly. I have heard from him such 
appreciations for Professors Shorey and Balasubramanian of their nice mathematical contributions. I too was fortunate to get such appreciations from him on a few occasions. I feel that this is the right moment to record such an experience of mine from him. I recall here the year 1993-1994. During this period, I was working on the zeros of quadratic zeta-functions on the critical line over short intervals. I wrote a manuscript (first draft) which slightly improves the length of the short interval (of a result of Bruce Berndt, for the imaginary quadratic field case, and of a result of K. Chandrasekharan and Raghavan Narasimhan, for the real quadratic field case) so that a zero of quadratic zeta-functions exists in such a shorter interval. I went with the manuscript to his office in the morning around 10 O'Clock on the next day, told him about the result I had gotten and requested him to check the manuscript. He was a bit hesitant and halfhearted to check my manuscript. The reason for his reluctance was that during a tea-table conversation, Prof. K. Chandrasekharan told Prof. K. Ramachandra that it would be very difficult to improve their result. I politely requested Prof. Ramachandra to check my manuscript and find a flaw and then let it go to the dustbin. After my lunch at the cafeteria (my family was away on that day), I went home and peacefully slept in the afternoon. On hearing my house door calling bell at around $4 \mathrm{pm}$ that day, I opened the door; to my surprise, Prof. Ramachadra was standing outside the door full of joy (I could see from his face). I understood from him that he sat with my manuscript after I left his office and checked it thoroughly all through the day. He congratulated me for this nice result and started telling about it to all our faculty members the next day. He was such a nice person and this incident still runs in my mind as one of my green memories. I should also mention here that later developments show that there are certain improvements on the imaginary quadratic field case whereas in the real quadratic field case my result still stands as such.

He started on his own the Journal "Hardy-Ramanujan Journal" (devoted to primes, Diophantine equations, transcendental numbers and other questions on $1,2,3,4, \ldots$ ) with Professor R. Balasubramanian and Professor K. Ramachandra as editors and published it successfully for the past 33 years. I hope that this journal will be continued.

Definitely, he was very generous. A very good Indian number theorist who died at an early age left behind his spouse with four children. For those children's education, he used to send money every year. I know this very well because I myself have sent money on his behalf sometimes.

When I received a phone call from his brother-in-law in the early morning 2.00 O'Clock on 18th January 2011 about his sad demise, I was naturally quite shocked and it took me almost 2 hours to recover myself. The only solace to my heart and my mind is that I was fortunate to be with him at the Ramaiah Hospital in Bangalore for at least five days in December 2010. 
Prof. Ramachandra was one of the best mathematicians of our country and his passing away is a very big loss generally to our Nation and in particular to all Number Theorists worldwide. I really do not find any words to console his family at this critical moment. Though he is no more physically, I am sure that he will be living with us and he will be remembered for his excellent contributions to the subject Number Theory in the years to come.

I pray to the Almighty that his soul rests in peace.

A. Sankaranarayanan

School of Mathematics

TIFR, Mumbai-400 005

\section{Mangala Narlikar}

When we came to Mumbai at the end of 1972 with two small daughters, we got to live in the TIFR housing colony as my husband was a professor in the department of Physics there. More than six years before that, I was first a research student and then research associate in the School of Mathematics there. In my spare time, I started going to the same place to see if I can work in Mathematics again. My interest was in Analysis and related subjects and I started attending some lectures along with new students. Professor K. Ramachandra whom I had seen but not interacted with before, was lecturing on Analytic Number Theory and I liked those lectures. When Professor Ramachandra found that I wished to study that branch of mathematics, he gave all the encouragement. Due to my household responsibilities, sometimes the timing of the lecture was changed to suit me. I found his lectures as well as those of R. Balasubramanian very interesting and inspiring. Along with these two people, Professor Shorey, Dr Srinivasan, Mr Rane etc made a very lively group of number theorists. That I managed to work for a PhD is due to the encouragement of Professor K. Ramachandra. Later I also worked as a Pool Officer under his guidance.

Professor Ramachandra's only passion seemed to be to work in Mathematics and to encourage people who wished to work in the field. This was amply demonstrated when he felicitated and offered a purse from his own pocket to Mr Kaprekar. $\mathrm{Mr}$ Kaprekar was a school teacher in Nasik, who worked by himself in number theory and recreational mathematics and tried to inspire school children with the subject.

Later, Professor Ramachandra was our next door neighbor and both he and his wife Saraswati were very friendly to our youngest daughter Leelavati.

Mangala Narlikar.

\# 6, Khagol Society

Panchavati, Pashan

Pune 411008. 


\section{K. Srinivas}

\section{Ramachandra: Personal reminiscences}

There are some who do mathematics and there are others who live in mathematics. Ramachandra belonged to the second category. Mathematics was everything for him. The analytical properties of the Riemann zeta-function, $\zeta(s)$, was something that was close to his heart. The ease with which he would derive deep properties of $\zeta(s)$, many times using only simple arguments like maximum modulus principle, Cauchy's residue theorem, Hölder's inequality, partial summation formula ... exhibits his deep understanding of the subject. One of the missions he undertook in recent years was to establish the known properties $\zeta(s)$ without using functional equation for $\zeta(s)$ ! To strengthen his point he established the proof of the infinitude of simple zeros of $\zeta(s)$ on the critical line in a very simple, yet elegant way without the use of functional equation. Another desire he had was to see a simple proof of Fermat's Last Theorem.

He believed in the classical Indian Gurukul system at heart. His Gurus were Srinivasa Ramanujan, Paul Erdös, I. M. Vinogradov, Carl Ludwig Siegel, Atle Selberg, Roger Heath-Brown, ...just to name a few. The name of Srinivasa Ramanujan, in particular, would overwhelm his heart with emotions and sometimes tears would roll out from his eyes. On one occasion, he was invited to deliver a talk on the works of Ramanujan in the Homi Bhabha auditorium, TIFR. He was speechless for considerable amount of time as he was displaying the picture of Srinivasa Ramanujan. He was greatly influenced and affected by the life and works of Ramanujan. He tried to imbibe the values derived from Ramanujan's life. Like the famous taxi-cab number 1729, Ramachandra discovered, while in college, that 3435 is the only number with the property

$$
u v w x=u^{u}+v^{v}+w^{w}+x^{x} \quad \text { i.e., } \quad 3435=3^{3}+4^{4}+3^{3}+5^{5} .
$$

Apparently, his principal had a car with this number displayed in the number plate! To express his gratitude towards Ramanujan and also to facilitate publication of quality papers purely devoted to analytic number theory, he (along with R. Balasubramanian) founded the Hardy-Ramanujan society and brought out the Hardy-Ramanujan journal starting from 1978. This journal attracts a number of good papers from reputed mathematicians. A section of this journal is devoted to popularize some important results which deserve to be well known. As a token of appreciation for good work, they instituted the Distinguished Award of the HardyRamanujan society. Over the years the award has achieved considerable respect in the mathematical community.

It is said that without him Analytic number theory would have disappeared from the Indian scene in the seventies. His brave fight to defend the subject and the interests of fellow number theorists eventually resulted in the formation of a strong analytic number theory group in India which enjoys considerable international 
reputation. He was greatly concerned about the future of analytic number theory in India. It was his dream that in the land of Ramanujan, analytic number theory should flourish beyond limits. To popularize analytic number theory he wrote several expository articles on topics like Riemann Hypothesis, Brun sieve, prime number theorem, Waring's problem, Ramanujan's circle method .... I hope that the analytic number theory group would take his mantle forward in the years to come and make his dreams come true.

To his credit, he has about two hundred published research papers and four books on number theory. His PhD students include S. Srinivasan, T. N. Shorey, M. Narlikar, R. Balasubramanian, V. V. Rane, A. Sankaranarayanan, K. Srinivas and Kishor Bhat. I was fortunate to have him as my thesis advisor. As an advisor, he was completely different from others. He would propose a problem and would enquire about the progress at least three times a day, everyday, until one day he would himself declare that this is enough for a paper! Before we would get into a celebration mood, which invariably meant to have a coffee and share a cake in the west canteen of TIFR, he would be ready with either an extension of the current problem or posing a different problem and this routine continued until I finished my thesis. This aspect of his personality shows his ability to initiate certain themes which paved way for others to pursue further and thereby enriching the literature. He would advise in a fatherly way to go deep into a particular topic, rather than accumulating a superficial knowledge of too many things.

The most remarkable quality of his was his simplicity, honesty and compassion for fellow human beings. I have never heard him boasting about himself or his achievements. He would, in fact, speak very fondly about the achievements of his students. Even though he commanded great respect from all, he never succumbed to the temptations of power and greed. The demise of Ramachandra is not only an irreparable loss to his family but also to the entire mathematical community.

K Srinivas

Institute of Mathematical Sciences

CIT Campus, Tharamani, Chennai 600 113, India

email: srini@imsc.res.in

\section{Kishor Bhat}

Some Reminiscences about Professor K Ramachandra

Talking about Professor Ramachandra has never done justice to him. I was his final student, working with him from 2005 until his passing. Being with him was an incredible experience, but I suppose many people can say that about their professors. I thought the best thing I could do was to share my experiences with Professor Ramachandra. When I worked with Professor Ramachandra, for reasons that do not 
require too much explanation, I kept a record of my experiences. Below are some edited excerpts:

A day with Professor Ramachandra:

Today I came into work late. Professor Ramachandra as usual came on time, and was prompt. Since I am his student, and the only other number theorist at NIAS, he was looking for me.

I met with Professor Ramachandra when I got in. He wanted to simplify a proof we were working on, and we went off to discuss different ideas about how to simplify our proof. He insisted that everyday, we were to have a discussion on mathematics, and he wanted to make sure I was making progress on my work.

In NIAS, there is a discussion room with three blackboards that the mathematicians like discussing in. We went into the room and suggested certain ways to improve the proof. The progress was not linear. Sometimes we felt we would have already solved it, and sometimes we would not know what to do. At the end of the day, we both improved on our previous result by a small amount, but did not feel ready. This is what working with Professor Ramachandra was like. He never knew the answers, but he would work with you to get them. He did not like classes, but would encourage his students to do research from day one. "If you want to learn to swim, you must go to the middle of the ocean and swim" was his motto.

Another day:

I met Professor Ramachandra in the morning. He asked me if there was any news from Acta Aritmetica. For those of you who do not know, Acta Arithmetica was Professor Ramachandra's favorite periodical. Even though it was a quarterly, he would always anxiously go to the library every Thursday to check for the next copy. In his final year, we were able to access copies on the internet, so I, as his student, would check online for the latest copy. There was no new issue that day.

Professor Ramachandra and I had a discussion on numbers that are the sum of squares. He gave me some problems to work on the day before, and today he gave me some hints to his exercises, which I confused with some other exercises he gave on square-free numbers. This was common. Ramachandra was one of the most focused mathematicians we knew, but in that focus, there was a huge world. He would tell me not to get confused by people who do high-dimensional analysis. "The first dimension is already very complicated."

He called me during lunch and told me that we were required to write a bi-annual report, which he wrote on behalf of the two of us. He mentioned the paper that we both worked on. Ramachandra would tell people that the work was really mine. This was his way, he really cared about, not just promoting his own students, but also encouraging newcomers to the field. Since he felt I was a novice, he wanted me to do well. 
In the evening, Ramachandra called me from his residence and asked if I was thinking about the problem we discussed. I said I was and he was pleased, and wished me a happy Ugadi (Kannada New Year).

Another day:

Today Ramachandra gave a lecture. Here are the notes of that lecture.

Ramachandra, who seemed a little irritated, began his lecture. He commented on the difficulty of notation, but added that the difficulty in working through the theorem will add to the extraordinariness of the theorem. "The more you struggle to get a result, the nicer the result is!" he would say, or "We need to prove a complicated statement to prove a nice theorem." Professor Ramachandra was always filled with statements like this. For him, the difficulty of work was part of its joy. He would repeat this sentiment many times during the lecture. It was good for me as a student to hear this, as it made my own failures more bearable, and would encourage me to do things, even when in all likelihood the effort would end in frustration.

Ramachandra was one of those exceptional individuals. He may have been one of the few Professors I would habitually refer to as sir (in no small part because he always referred to me as sir, despite our 50 year age difference). Working with Ramachandra was always an experience. I always had my bag filled with Ramachandra stories. Most of them were so fantastic, that people would scarcely believe that there was such a person who could be so focused a mathematician. Those who have had the occasion to meet him, learn that it was no exaggeration. He really was the focused single-minded genius I said he was. It's a pity. After today no one will believe me.

Those of us who have been part of the mathematics group in NIAS miss him. We know that mathematics as a whole suffer his loss. Those of us who work with the numbers that he so dearly loved know that they are not as easy to work with now that he is no longer with us. 